\title{
Shear-flexure interaction in the critical sections of short coupling beams
}

\author{
Boyan I. Mihaylov, Renaud Franssen* \\ Department of ArGEnCo, University of Liege, Quartier Polytech 1, 9 Allée de la Découverte, 4000 Liege, Belgium
}

\section{A R T I C L E I N F O}

\section{Article history:}

Received 24 April 2017

Revised 6 September 2017

Accepted 12 September 2017

\section{Keywords}

Short coupling beams

Shear sliding

Mechanical model

Strain compatibility

\begin{abstract}
A B S T R A C T
Heavily-loaded short coupling beams with large amounts of transverse reinforcement fail in sliding shear or diagonal compression under the complex interaction between shear and flexure. These failure modes often occur after yielding of the flexural reinforcement and limit the displacement capacity of the member. To study such failures, this paper compares experimental results with predictions of models with various levels of complexity. It is shown that complex nonlinear finite element models (FEM) can capture adequately the entire behaviour of short coupling beams, while the classical flexural model produces unconservative strength predictions. It is also shown that strut-and-tie models are reasonably conservative provided that their geometry is selected to maximize the strength predictions. To produce similarly adequate strength predictions as those of the FEM - while at the same time maintaining the simplicity of the flexural model - the paper proposes a mechanical model based on strain compatibility. The main assumption of the model links the principal compressive strains in the critical section to the longitudinal strains in the tension zone. It is shown that the model captures well the effect of different test variables on the shear strength. When applied to a database of 24 tests, the model produced an average shear strength experimental-to-predicted ratio of 1.12 with a coefficient of variation of $8.4 \%$.
\end{abstract}

(c) 2017 Elsevier Ltd. All rights reserved.

\section{Introduction}

Coupling beams in reinforced concrete wall structures of buildings serve to link the individual walls in a stiff lateral-load resisting system. These members work in double curvature with high shear forces and often feature small span-to-depth ratios $(\mathrm{a} / \mathrm{h} \leq 2.5)$. Such short members are susceptible to shear failures that occur along wide diagonal cracks with yielding of the transverse reinforcement as illustrated in the left diagram in Fig. 1a [1]. To suppress diagonal tension failures, the coupling beams are provided with large amounts of stirrups or diagonal reinforcement. However, when the opening of diagonal cracks is suppressed with stirrups, the failure develops in the end sections under the complex interaction between shear and flexure. This failure mode is characterized by crushing of the concrete prior to or after the yielding of the flexural reinforcement. The failure occurs with sliding deformations as illustrated in the right diagram in Fig. 1a (sliding shear failure) or with lateral bursting of the web (diagonal compression failure). This paper focuses on the modelling of sliding shear and diagonal compression failures in short coupling beams without diagonal reinforcement.

\footnotetext{
* Corresponding author.

E-mail addresses: boyan.mihaylov@ulg.ac.be (B.I. Mihaylov),r.franssen@ulg.ac. be (R. Franssen).
}

Short coupling beams do not obey the plane-sections-remainplane hypothesis and therefore cannot be modelled based on the classical beam theory. Instead, such members are typically designed based on strut-and-tie models (STM) such as the one shown in Fig. 1b. In this model the shear force is resisted by two inclined struts linked by a vertical tie representing the transverse reinforcement. Such model was used for example in the design of the coupling beams of Burj Khalifa [2] based on the ACI strutand-tie provisions [3]. In addition to the truss mechanism depicted in Fig. 1b, other more complex models also include a direct diagonal strut between the end nodes of the beam. According to the strut-and-tie models, the failure of the end sections can either occur due to yielding of the longitudinal tie or crushing of the inclined strut. If the failure is governed by strut crushing, this will indicate shear sliding or diagonal compression failure of the member. However, nonlinear finite element simulations performed by Lee et al. [2] showed that coupling beams can have significantly larger shear capacities than predicted by the strut-and-tie model in Fig. 1b. While such conservatism is usually appropriate in new design, more accurate models are required for the assessment of existing structures or in cases of heavily loaded coupling beams. Moreover, because strut-and-tie models are not well suited for calculating deformations, there is need for approaches that account for the strains in the critical end sections. Predicting these deformations is important for evaluating the ductility and displacement 

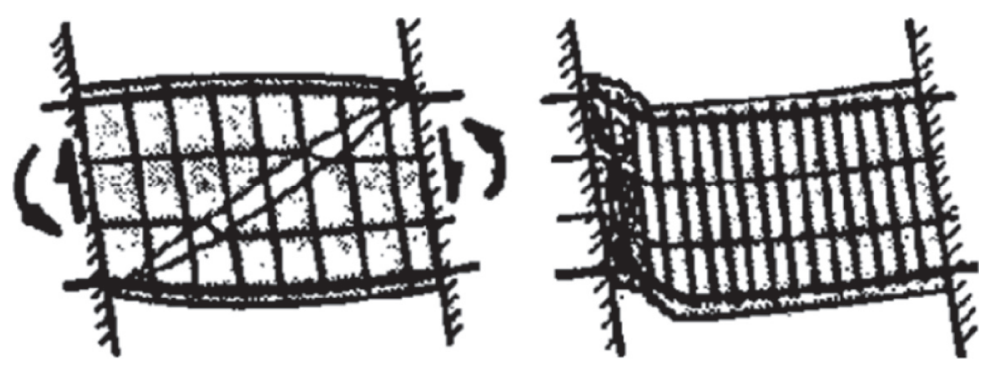

a) Failure modes (adapted from Paulay and Priestley [1])

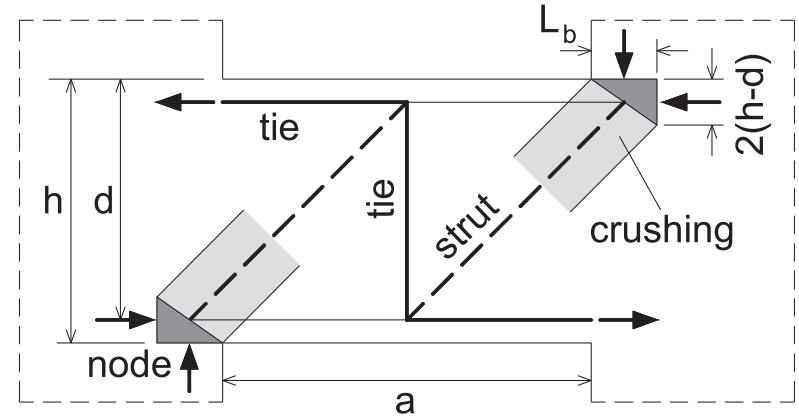

b) Strut-and-tie model

Fig. 1. Short coupling beams.

capacity of the coupling beams. Therefore, the main goal of this paper is to propose a simple and accurate model for evaluating the deformations and shear-flexure interaction in the critical end sections of short coupling beams. The model will be developed and validated with the help of data from experimental studies ([4-11]) and nonlinear finite element simulations.

\section{Observed behaviour of coupling beams}

The behaviour of short coupling beams will be first discussed with the help of a test from an early experimental program by Paulay [4]. The test specimen, named beam 312, had a $152 \mathrm{~mm}$ by $787 \mathrm{~mm}$ rectangular cross section and a shear span-to-effective depth ratio $\mathrm{a} / \mathrm{d}=1.42$, see Table 1 . The longitudinal reinforcement of the beam consisted of symmetrical top and bottom bars with a ratio $\rho_{1}=1.58 \%$, while the transverse reinforcement consisted of stirrups with $\rho_{v}=1.65 \%$. The specimen was subjected to symmetrical double curvature bending (zero moment at midspan) by forces applied on end blocks simulating portions of adjacent shear walls. The load was applied in a reversed cyclic manner with the amplitude of the cycles being close to the strength of the beam.

The global response of the test specimen in terms of shear force vs. chord rotation is shown in Fig. 2a. Following the initial stiff response of the uncracked beam, a significant reduction of stiffness occurred when the load reached about $20 \%$ of the maximum load. This change of behaviour was caused by the propagation of steep flexure and flexure-shear cracks near the end sections of the beam where the bending moment was maximum. As the load was increased further, more flexure-shear cracks developed in the shear span followed by the propagation of a major shear crack. As evident from Fig. 2b, this crack extended from corner to corner of the beam along the diagonal of the shear span. The first load reversal was performed soon after the flexural reinforcement yielded in the end sections resulting in a plateau in the global response at $\mathrm{V} \approx 640 \mathrm{kN}$. A similar loading protocol was followed in the "negative" direction until a complete symmetrical crack pat- tern developed across the shear span. The longitudinal reinforcement also yielded on the opposite side of the section, and the load-rotation curve developed a plateau at $\mathrm{V} \approx-600 \mathrm{kN}$. Limited yielding of the transverse reinforcement was also measured in the main diagonal crack. Following this initial loading, two additional full load cycles were applied on the specimen resulting in increasing plastic rotations. Eventually, the concrete in the end sections crushed under the combined action of shear and flexure limiting the displacement capacity of the member, Fig. 2c. This crushing was accompanied by visible sliding deformations in the end sections, and therefore the beam failed in sliding shear. In other tests from the same experimental program the crushing of the concrete did not occur with sliding but with lateral bursting of the compression zone. This latter type of failure is typically defined as diagonal compression or shear compression failure. It should be noted however that in many cases the difference between sliding shear and diagonal compression failure is very subtle. Both failure modes occur when the beam is provided with sufficient transverse reinforcement to suppress shear failures along the major diagonal crack.

Provided that the transverse reinforcement exceeds the amount required for suppressing a diagonal tension failure, the strength of the beam is not significantly influenced by the transverse reinforcement ratio. This is demonstrated in Fig. 3 with the help of specimen 312 and two companion tests (beams 311 and 313, see Table 1 ). The stirrup ratio of the specimens varied from $0.88 \%$ to $2.52 \%$ while the shear force at failure remained approximately constant. The three specimens failed with yielding of the longitudinal reinforcement and crushing of the concrete in the end sections. Because the reinforcement yielded, a first approximation to the failure load can be obtained based on the classical planesections-remain-plane approach for flexure which does not account for the effects of shear. While strictly speaking this approach is not applicable to short members, it is used here to provide a reference value for the strength of the end sections. The flexural strength calculated with the classical model is divided by one- 
Table 1

Test specimens by Paulay [4].

\begin{tabular}{|c|c|c|c|c|c|c|c|c|c|c|c|c|}
\hline Beam name & $\mathrm{a} / \mathrm{d}$ & $\mathrm{b}(\mathrm{mm})$ & $\mathrm{d}(\mathrm{mm})$ & $\mathrm{h}(\mathrm{mm})$ & $\mathrm{a}(\mathrm{mm})$ & $\rho_{1}(\%)$ & $\mathrm{f}_{\mathrm{y}}(\mathrm{MPa})$ & $\mathrm{f}_{\mathrm{c}}(\mathrm{MPa})$ & $\rho_{\mathrm{v}}(\%)$ & $\mathrm{f}_{\mathrm{yv}}(\mathrm{MPa})$ & Rep. mode & $\mathrm{V}_{\exp }(\mathrm{kN})$ \\
\hline \#393 & 1.11 & 152 & 917 & 991 & 1016 & 1.06 & 316 & 30.8 & 1.62 & 328 & S-SC & 849 \\
\hline \#311 & 1.42 & 152 & 714 & 787 & 1016 & 1.58 & 313 & 36.7 & 0.88 & 386 & DT & 651 \\
\hline \#312 & 1.42 & 152 & 714 & 787 & 1016 & 1.58 & 313 & 35.2 & 1.65 & 285 & $S$ & 642 \\
\hline \#313 & 1.42 & 152 & 714 & 787 & 1016 & 1.58 & 313 & 44.5 & 2.52 & 314 & $S$ & 660 \\
\hline \#244 & 2.27 & 152 & 536 & 610 & 1219 & 1.82 & 321 & 36.3 & 1.58 & 307 & $\mathrm{~S}$ & 405 \\
\hline
\end{tabular}

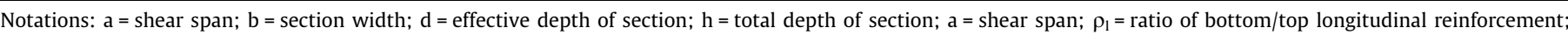
$f_{y}=$ yield strength of longitudinal reinforcement; $f_{c}=$ concrete compressive strength; $\rho_{v}=$ stirrup ratio; $f_{y v}=$ yield strength of stirrups; $V_{\text {exp }}=$ measured shear strength. Reported failure modes: SC - shear compression; S - sliding shear; DT - diagonal tension.

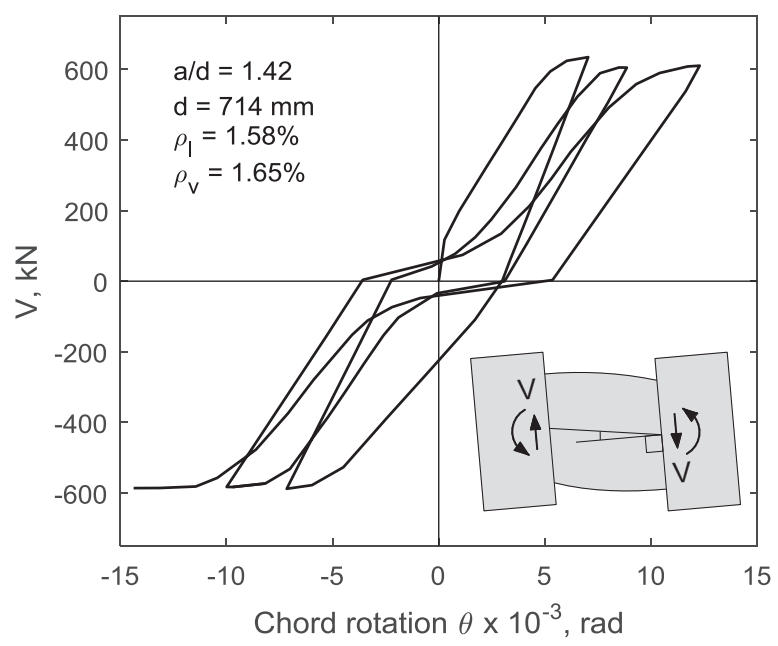

a) Measured load-deformation response

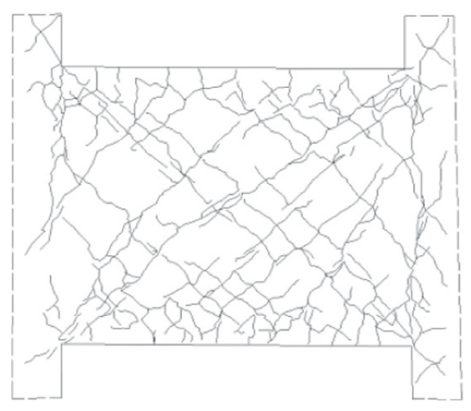

b) Final crack pattern

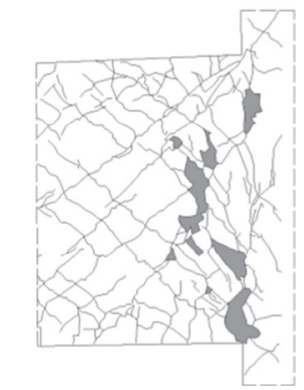

c) Sliding shear failure
Fig. 2. Behaviour of a coupling beam (test specimen 312 [4]).

half of the length of the shear span to obtain the shear force at failure $V_{\text {max. }}$. The results from these calculations for the three beams with variable stirrup ratio are shown with a dashed line in Fig. 3. It can be seen that such simple approach results in a significant overestimation of the strength of the beams even when the flexural reinforcement yields. The resulting average strength experimentalto-predicted ratio for the three beams is 0.79 . This shows that the shear force in the critical end sections with vertical cracks causes a significant reduction of flexural capacity.

It is also of interest to compare the experimental results with the predictions of the strut-and-tie model in Fig. 1b which accounts for the effects of shear. As mentioned earlier, the failure of the end sections in this model can either occur due to the yielding of the longitudinal reinforcement or crushing of the inclined strut. In order to calculate these two failure modes, it is necessary

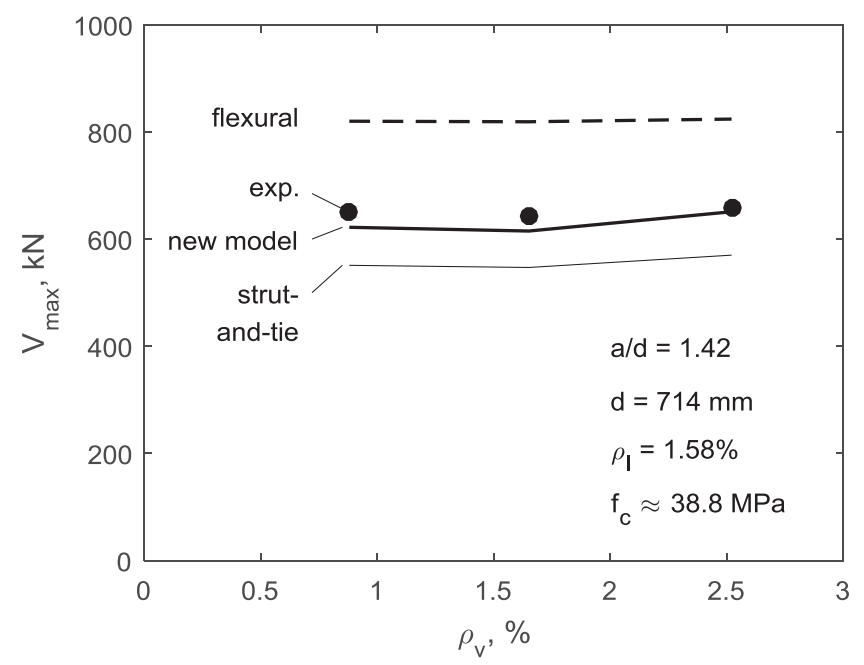

Fig. 3. Effect of transverse reinforcement on sliding shear strength (tests by Paulay [4]).

to determine the inclination of the strut which depends on the horizontal dimension of the nodal zone $\mathrm{L}_{b}$ in the adjacent wall, see Fig. $1 \mathrm{~b}$. The larger is length $\mathrm{L}_{\mathrm{b}}$, the smaller is the inclination of the strut and the larger is the width of the strut. Because the capacity of the strut is proportional to its width, the shear corresponding to strut crushing increases with increasing $\mathrm{L}_{\mathrm{b}}$. At the same time, as $\mathrm{L}_{b}$ increases, the lever arm between the longitudinal compressive and tensile forces in the end section decreases, and therefore the shear corresponding to yielding of the longitudinal reinforcement also decreases. Because strut-and-tie models are typically conservative, it is proposed to choose $\mathrm{L}_{\mathrm{b}}$ such that to maximize the shear strength prediction. This is achieved when the shear corresponding to strut crushing is equal to that causing flexural yielding. The value of $L_{b}$ that satisfies this condition can be found by a trialand-error procedure. Following this approach, the calculations for beams 311-313 were performed using a strut crushing stress of $\min \left[0.55\left(30 / \mathrm{fc}^{1 / 3}, 1\right] \mathrm{f}_{\mathrm{c}}\right.$ according to the strut-and-tie provisions of the fib Model Code 2010 (MC2010) [12]. This is a constant crushing stress while the shear provisions of MC2010 also provide methods to refine the 0.55 factor as a function of the state of strains in the concrete. As evident from Fig. 3, the STM model results in conservative strength predictions with an average experimental-topredicted ratio of 1.17 . Similarly conservative results are obtained by using strut crushing stresses according to other codes $([3,13])$. Because the strut-and-tie model is conservative and the flexural model is unconservative, this paper will propose a model that significantly improves the shear strength predictions while maintaining the simplicity of the flexural model.

For the purpose of developing the model, it is important to consider the distribution of the strains in the longitudinal reinforcement of short coupling beams failing in sliding shear. As evident 
from Fig. 4, the strains measured in beam 312 significantly deviated from the linear distribution predicted by the classical beam theory for slender beams. While the maximum tensile strain occurred on the flexural tension side of the end sections, the strains did not decrease to zero in the middle of the shear span where the bending moment is zero. More importantly, following the propagation of the major diagonal crack, the strains became tensile along the entire shear span, approaching zero on the flexural compression side. As a result, the longitudinal reinforcement on the flexural compression side of the end sections is not effective in resisting the bending moment. The moment resistance of these sections is provided mainly by the compression resistance of the concrete and the tension force in the reinforcement on the flexural tension side of the section as in the strut-and-tie model in Fig. $1 \mathrm{~b}$.

Another important observation concerns the effect of load reversals on the response of test specimen 312. It can be seen from Fig. 2a that, while the loading history resulted in a significant increase of deformations from cycle to cycle, the beam was able to maintain a maximum resistance that was about $7 \%$ smaller than the resistance reached during the initial monotonic loading. This is an indication that the strength of the beam can be estimated reasonably well without an explicit consideration of the effects of load reversals. A similar observation can be made from two other tests from the same experimental program on nearly identical beams (tests 242 and 243) where one of the beams was loaded monotonically and the other cyclically. Both beams failed due to crushing of the concrete in the end sections after yielding of the longitudinal reinforcement. The monotonically-loaded beam, which had a $21 \%$ higher concrete compressive strength, was 6\% stronger than its companion beam subjected to cyclic load. While these results are not conclusive and the effect of load reversals in short members is still being studied, the model developed in this paper will not account explicitly for cyclic strength degradation.

\section{Finite element analysis of coupling beams}

\subsection{Finite element model}

To gain further insight into the sliding shear and diagonal compression failures of short coupling beams, the behaviour of selected test specimens is simulated with a nonlinear finite element (FE) model. The FE analyses were performed with program VecTor2 based on the Disturbed Stress Field Model (DSFM [14]). The DSFM is a smeared rotating crack model that originates from the modified compression field theory for reinforced concrete elements subjected to shear [15]. In the DSFM, the cracks are assumed parallel to the principal compressive stress directions in the concrete, while the principal strain directions deviate from the stress directions due to slip displacements in the cracks. The slip displacements and crack widths are used to calculate aggregate interlock stresses transferred across the cracks. In addition to aggregate interlock, the DSFM also accounts for the tension stiffening and softening of the concrete, compression softening and confinement of the concrete, as well as the yielding of the reinforcement. To ensure that the analyses can be easily reproduced, these effects were modelled based on the default relationships implemented in VecTor2. The only exception is the compression behaviour of the concrete for which the Popovics model for normal strength concrete is preferred.

Fig. 5 shows the finite element model of beam 312. The model consists of quadrilateral plane-stress elements for the concrete and truss elements for the top and bottom longitudinal reinforcement. Bond elements were introduced between the quadrilateral and truss elements to capture slip displacements. Since the stirrups were densely spaced, they were represented as smeared vertical
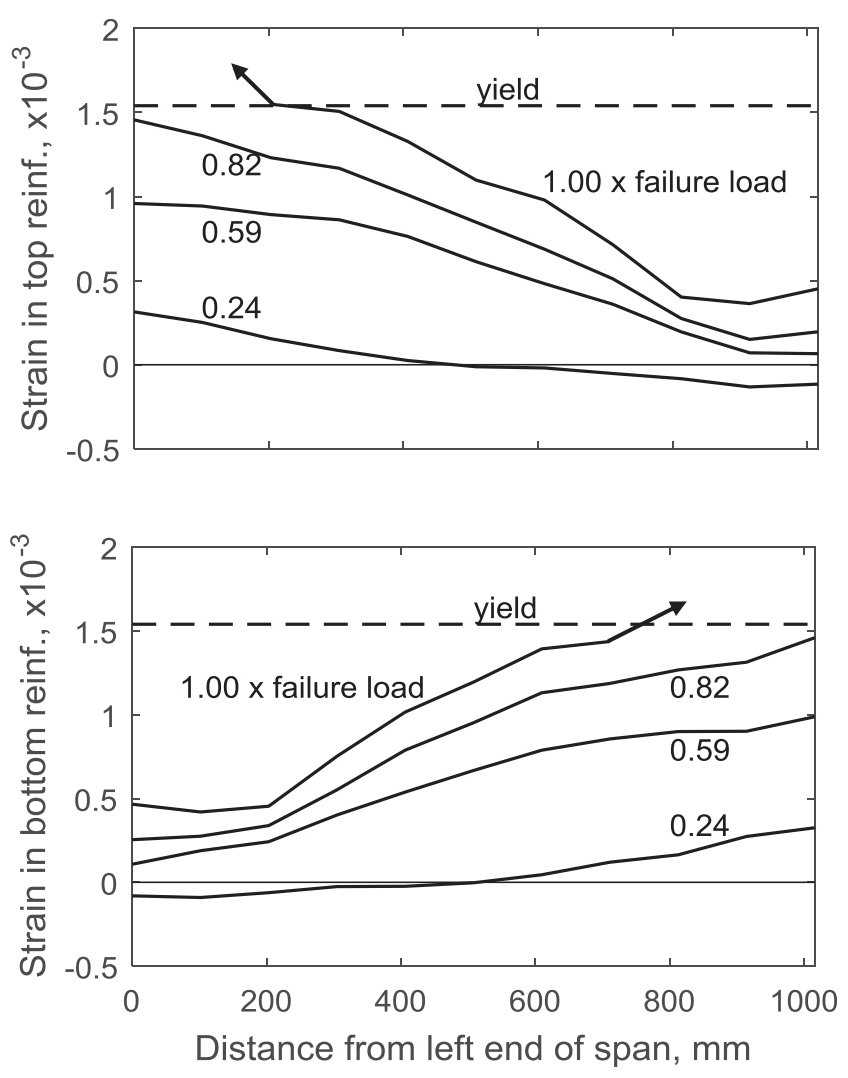

Fig. 4. Distribution of strains along top and bottom longitudinal reinforcement (test specimen 312 [4]).

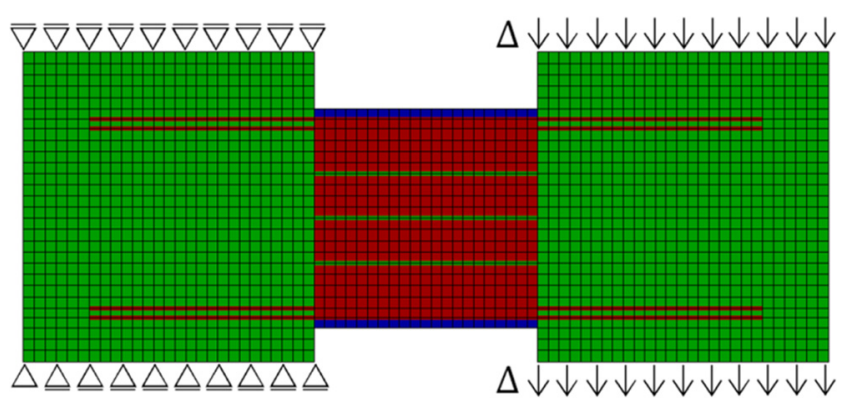

Fig. 5. Finite element model of coupling beam (program VecTor2 [14]).

reinforcement in the quadrilateral elements. The top and bottom concrete cover of the longitudinal reinforcement in the shear span was modelled with plain concrete elements. The shear force and bending moments were introduced in the shear span via heavily reinforced concrete blocks on each side of the beam. One of the blocks was clamped while the other was subjected to imposed vertical displacements along its top and bottom edges. Because the vertical displacements are constant along the block, they restrain its rotation while allowing unrestrained horizontal movements. The displacements were increased monotonically to capture the entire behaviour of the beam under symmetrical doublecurvature bending, including the post-peak response.

\subsection{Comparisons with test results}

The main results from the FEM simulations are summarized in Figs. 6 and 7. Fig. 6b shows the predicted crack and deformation patterns of specimen 312 at failure. As evident from the diagram, 

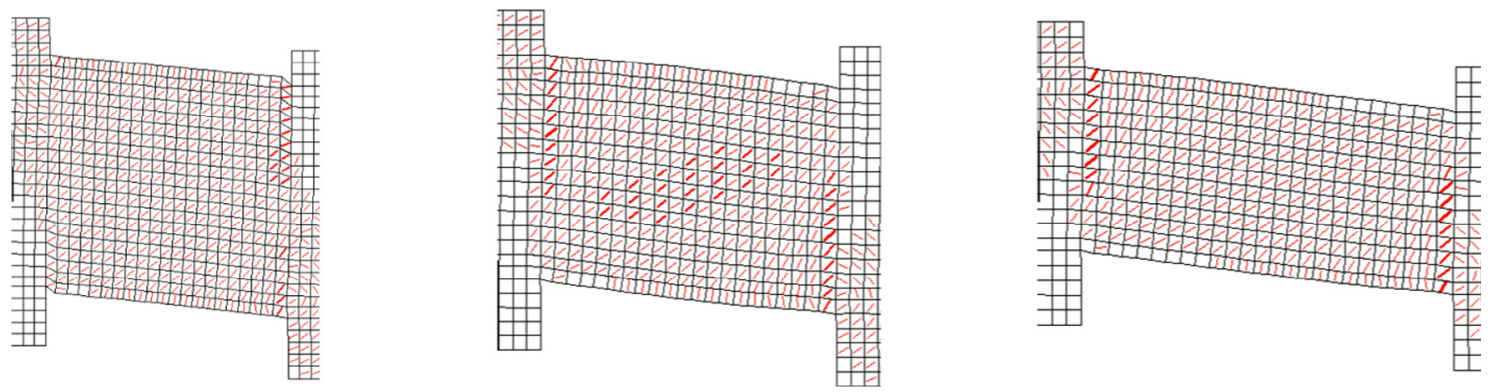
a) Specimen $393-a / d=1.11$ and b) Specimen $312-a / d=1.42$ and c) Specimen $244-a / d=2.27$ and $\rho_{l}=1.06 \% \quad \rho_{l}=1.58 \% \quad \rho_{l}=1.82 \%$

Fig. 6. Predicted crack and deformation patterns at failure (postprocessor Augustus [16]).

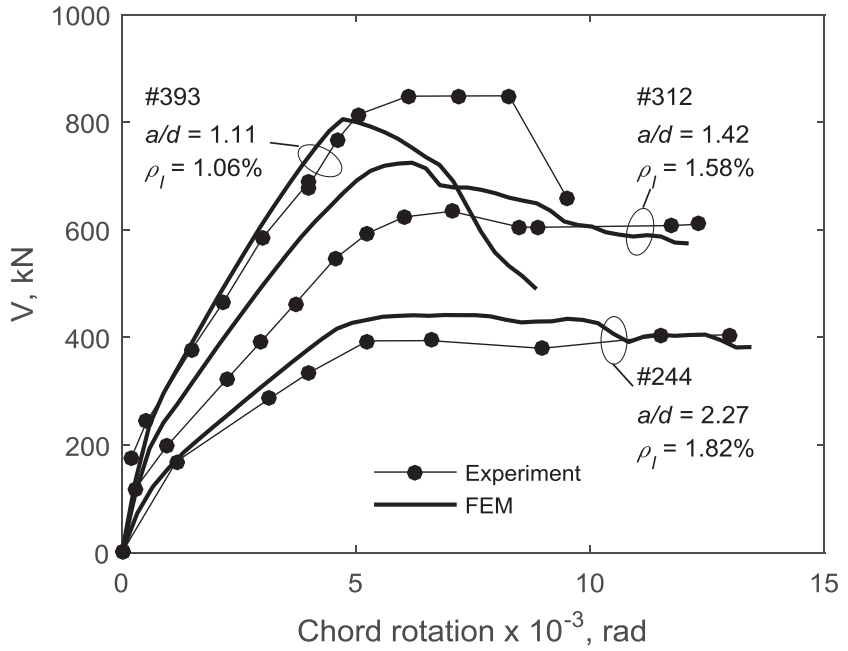

Fig. 7. Measured and predicted load-deformation response of short coupling beams (tests by Paulay [4]).

the predicted failure mode was similar to that observed in the test: yielding of the longitudinal and shear reinforcement as well as sliding shear in one of the end sections of the beam. Similar failure mode was predicted for two other specimens from the same experimental program for which the shear reinforcement remained elastic, see Fig. 6a and c. The three specimens differed mainly in terms of the a/d ratio which was varied from 1.11 to 2.27 by decreasing the depth of the section, see Table 1 . The other important variable was the ratio of the longitudinal reinforcement varying from $1.06 \%$ in the deepest beam to $1.82 \%$ in the shallowest one. It can be seen from Fig. 6 that specimens 312 and 244 were predicted to develop wide cracks in the critical end section due to the yielding of the longitudinal reinforcement, while the reinforcement in specimen 393 was predicted to remain nearly elastic. These predictions agree well with the strain measurements performed in the tests.

Fig. 7 compares the measured and predicted load-deformation responses of the three beams. It can be seen that the depth of the section and the a/d ratio had a significant effect on the measured response. As the tests were performed under reversed cyclic loading, the experimental curves in the plot represent the envelope of the full measured load-deformation responses in the direction in which the failure occurred. It can be seen that beam 244 with the smallest depth and largest a/d ratio was significantly softer and weaker than beam 393 with the deepest section and smallest a/d ratio. As the depth of the section decreased by $71 \%$, the shear strength increased by a factor of 2.1. This non-proportional strength increase shows that the smaller a/d ratio of beam 393 had a positive effect on the sliding shear resistance. At the same time, decreasing the a/d ratio resulted in decreased ductility and displacement capacity. As evident from Fig. 7, these trends are captured well by the FE model.

\subsection{Stresses and deformations in the critical end sections}

Having demonstrated that the FE model can capture the response of the test specimens, it is of interest to use the results from the simulations to further study how short coupling beams resist shear. Fig. 8a shows the orientation and relative magnitude of the principal compressive stresses in the shear span of beam 312 (green ${ }^{1}$ for minimum and blue for maximum compressive stresses). It can be seen that the stresses in the middle of the shear span are almost uniformly distributed across the depth of the section while the shear in the critical end sections is carried mainly in the compression zones. This is more clearly demonstrated in Fig. 8b which depicts the variation of the principal compressive stresses across the end and middle sections. Based on this diagram, the depth of the compression zone in the end sections is estimated at $\mathrm{x}=395 \mathrm{~mm}, 55 \%$ of the effective depth of the section. For comparison, a flexural strength calculation based on the plane-sectionsremain-plane hypothesis produces $\mathrm{x}=92 \mathrm{~mm}$, only $13 \%$ of $\mathrm{d}$. This significant difference is due to the high shear forces in short coupling beams.

Another important observation can be made based on Fig. 8c which shows the angle of inclination of the principal compressive stresses across the end and midspan sections. It can be seen that in the middle section the angle is almost constant at about $34^{\circ}$, corresponding approximately to the angle of the diagonal of the shear span. Similarly, the angle in the end sections is approximately constant within the compression zone, but with larger values than in the middle section. This angle can be estimated from the equilibrium of the forces in the end section, neglecting the small tension in the reinforcement on the flexural-compression side of the section. Based on the moment equilibrium, the horizontal force in the concrete can be estimated as $C=V(a / 2) / z$, where $a$ is the length of the shear span and $\mathrm{z}$ is the lever arm of the internal horizontal forces in the section. Since the shear force V is resisted almost entirely in the compression zone, the angle of the resultant force in this zone with respect to the horizontal axis can be estimated as:

$\tan \theta_{c}=\frac{V}{C}=2 \frac{z}{a} \approx 2 \frac{0.9 d}{a}$

\footnotetext{
${ }^{1}$ For interpretation of color in Fig. 8, the reader is referred to the web version of this article.
} 

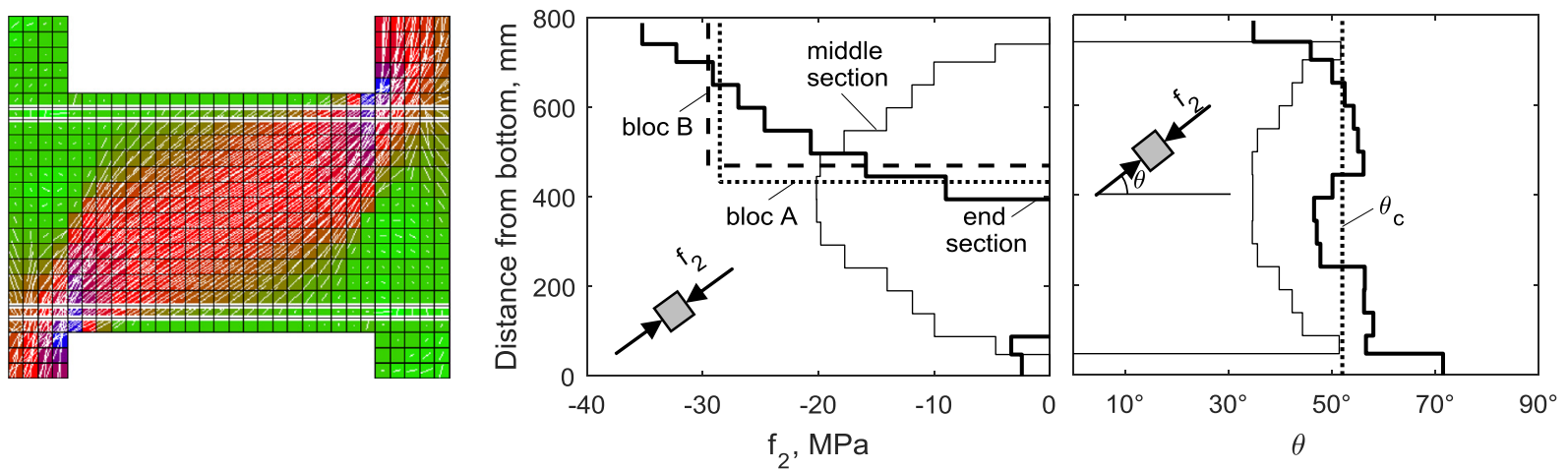

\section{a) Principal compressive stresses in b) Principal stresses in the end sections the concrete and at midspan}

\section{c) Angle of principal compressive stresses in the end sections and at midspan}

Fig. 8. FEM results for beam 312 .

The value obtained from this expression applied to beam 312 is $52^{\circ}$. As evident from Fig. 8c, this angle is almost exactly equal to the angle of the principal compressive stresses obtained from the finite element analysis.

Finally, it is of interest to study the distribution of the strains in the critical end sections of beams 244, 312 and 393 with variable a/ $\mathrm{d}$ ratio, see Fig. 9. The solid lines in the plots show the average horizontal strains in the concrete $\varepsilon_{\mathrm{x}}$ while the dotted lines show the minimum principal strains $\varepsilon_{2}$. It can be seen that strains $\varepsilon_{\mathrm{x}}$ do not follow the classical linear distribution assumed for the modelling of slender beams. Moreover, while in slender beams there is a well-defined zone of compressive strains $\varepsilon_{\mathrm{x}}$ on the flexuralcompression side of the section, the FEM results show that in short coupling beams the strains are tensile across the entire section, except for the concrete cover on the flexural-compression side. This is consistent with the test results presented in Fig. 4 which show that following the propagation of the major diagonal crack, the top and bottom longitudinal reinforcement become tensile along the entire shear span.

As compared to the longitudinal strains, the principal strains $\varepsilon_{2}$ outline a clear compression zone. This zone coincides with the zone of principal compressive stresses in Fig. $8 \mathrm{~b}$. Since the shear in the compression zone is carried by means of principal compressive stresses, it is the principal compressive strains that are of significance for predicting the shear resistance of the end sections. In other words, while the classical plane-sections-remain-plane approach focuses on the horizontal strains, the modelling of short coupling beams requires an explicit consideration of the inclined principal compressive strains. As with regards to the flexuraltension side of the section, the important strain remains $\varepsilon_{\mathrm{x}}$ as it is related to the stresses in the tension reinforcement. It is therefore necessary to establish a strain compatibility condition that links the strains $\varepsilon_{2}$ in the compression zone to the strains $\varepsilon_{\mathrm{x}}$ in the tension zone of the section.

\section{Mechanical model for end sections of short coupling beams}

\subsection{Model assumptions}

The strain diagrams in Fig. 9 are used to establish a kinematic assumption for short coupling beams in analogy to the planesections-remain-plane assumption for slender beams. As indicated in the plots, the strain diagrams in the critical end sections can be approximated with a straight line across the depth of the beam. This line is aimed at capturing the strains that are of importance for calculating the shear and flexural resistance of the section. In the compression zone the diagram approximates the principal compressive strains $\varepsilon_{2}$ while in the tension zone it approximates the horizontal strains $\varepsilon_{\mathrm{x}}$. As evident from Fig. 9, this linear approximation holds reasonably well even for the shortest beam with an a/d ratio of 1.11 . However, to avoid unrealistic predictions, this approach should not be applied to members with a/d $<1.0$ which are also rare in practice. The proposed assumption therefore establishes conditions for the compatibility of strains $\varepsilon_{2}$ and $\varepsilon_{\mathrm{x}}$ in coupling beams with $a / d \geq 1.0$. In addition, similarly to classical flexural strength calculations, it will be assumed that the failure occurs when the maximum principal compressive strain at the top of the section reaches $-3.5 \times 10^{-3}$. The plots in Fig. 9 show that this value corresponds reasonably well to the maximum principal strains predicted by the FE model at failure. With a fixed strain at the top of the section, the main unknown of the proposed method is the depth of the compression zone $\mathrm{x}$.

The assumptions of the proposed approach are illustrated in Fig. 10. The strain diagram is linear across the section and approximates different strains above and below the neutral axis. The strains below the axis are horizontal while those above the axis are inclined at angle $\theta_{c}$ estimated from Eq. (1). In addition to the strain distribution, it is also necessary to establish assumptions for the stresses in the section. The principal compressive stresses in the concrete $f_{2}$ are assumed parallel to the principal strains $\varepsilon_{2}$, and therefore are oriented at angle $\theta_{\mathrm{c}}$ with respect to the horizontal axis. As stresses $f_{2}$ are not horizontal, they do not act on the full depth of the compression zone $\mathrm{x}$. Instead, as indicated in the free-body diagram in Fig. 10, the stresses need to be integrated across area $\left(x \cos \theta_{c}\right) \cdot b$, where $b$ is the width of the compression zone. The distribution of the stresses in the compression zone can be obtained from the principal strains $\varepsilon_{2}$ by using an appropriate stress-strain relationship for concrete under uniaxial compression [17]. Owing to the restraint provided by the adjacent walls, compression softening effects in the concrete are neglected in the critical end sections. Also neglected is the shear carried by aggregate interlock across the vertical crack in the end section. This latter assumption is confirmed by the FE analyses and is particularly valid in the cases when the flexural reinforcement yields and the crack width becomes significant.

To simplify the calculations at ultimate limit state, the nonlinear distribution of the stresses $f_{2}$ is replaced by an equivalent rectangular stress block as in flexural strength calculations. This is possible because strains $\varepsilon_{2}$ are assumed to vary linearly in the compression zone and the width of the zone is constant. The depth 


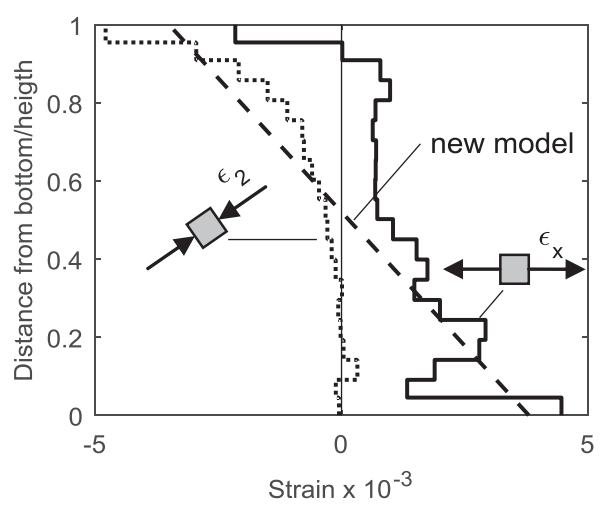

a) Specimen $393-a / d=1.11$ and $\rho_{l}=1.06 \%$

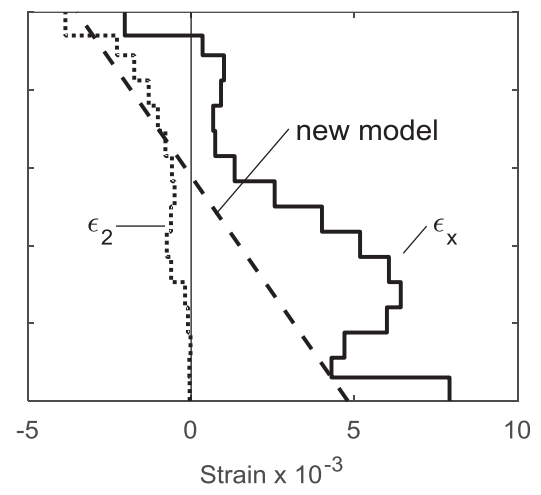

b) Specimen $312-a / d=1.42$ and $\rho_{l}=1.58 \%$

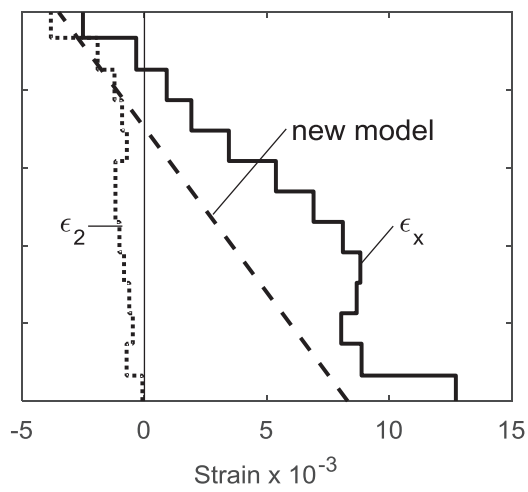

c) Specimen $244-a / d=2.27$ and $\rho_{l}=2.27 \%$

Fig. 9. Predicted strains in the end sections of short coupling beams at sliding shear failure.
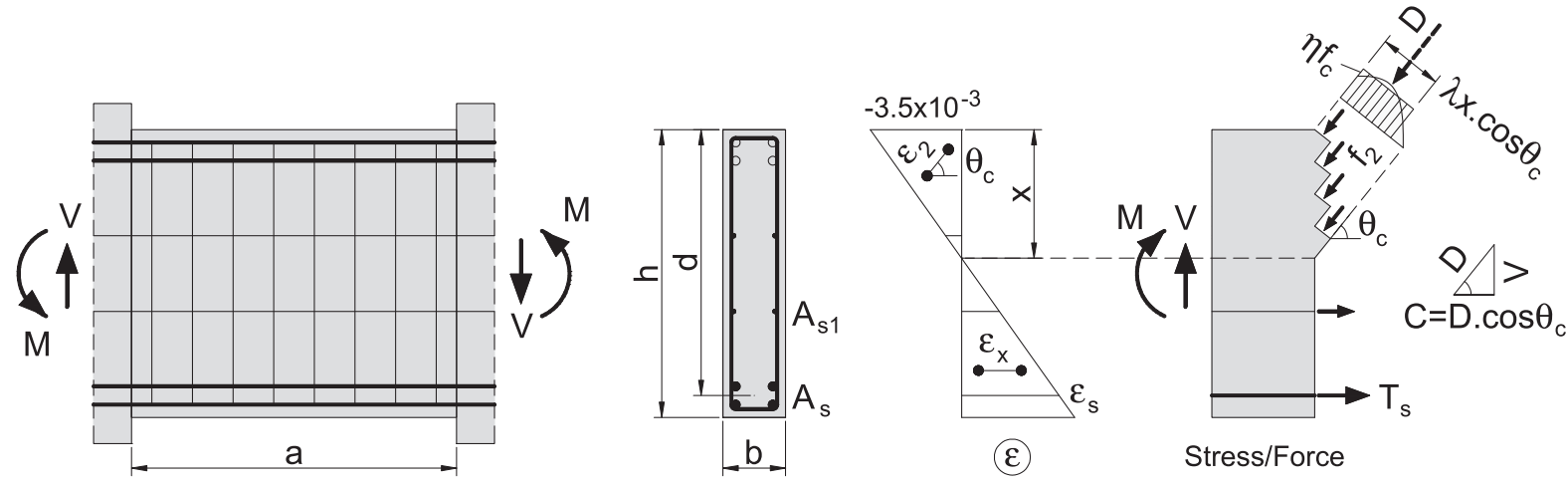

Fig. 10. Proposed model for the shear-flexure interaction in the end sections of short coupling beams.

of the stress block is $\lambda x \cos \theta_{c}$ while the magnitude of the stress is $\eta \mathrm{f}_{\mathrm{c}}$. Coefficients $\lambda$ and $\eta$ can be evaluated according to the flexural strength provisions of design codes $([3,13])$ or based on a parabolic stress-strain diagram for the concrete resulting in

$\lambda=\frac{4-\varepsilon_{t} / \varepsilon_{c 1}}{6-2 \varepsilon_{t} / \varepsilon_{c 1}}$

$\eta \lambda=\frac{\varepsilon_{t}}{\varepsilon_{c 1}}-\frac{1}{3}\left(\frac{\varepsilon_{t}}{\varepsilon_{c 1}}\right)^{2}$

where $\varepsilon_{\mathrm{c} 1} \approx 2 \times 10^{-3}$ is the strain at peak stress of the concrete. The parabola model provides reasonable accuracy for concretes with compressive strength of up to 40-50 MPa while stress block factors based on more general stress-strain relationships are available elsewhere [18].

Fig. 8b shows two rectangular block approximations of the principal compressive stresses obtained from the FEM analysis of beam 312. Block A is obtained directly from the stresses produced by the FE model by ensuring the static equivalence between the nonlinear and constant stress distributions. Block B on the other hand is obtained by using $\mathrm{x}=395 \mathrm{~mm}$ from the FE analysis and the stress block factors $\lambda$ and $\eta$ from Eqs. (2) and (3). It can be seen that for this beam the two rectangular stress blocks are almost identical, validating the proposed simplifying assumptions about the linear variation of the strains $\varepsilon_{2}$ and the use of concrete stress-strain relationships for uniaxial compression.

By using rectangular stress block factors $\lambda$ and $\eta$, the resultant diagonal compressive force $\mathrm{D}$ is expressed as:
$D=\lambda \eta \cdot f_{c} b \cdot x \cdot \cos \theta_{c}$

while its horizontal component $\mathrm{C}$ is

$C=D \cdot \cos \theta_{c}=\lambda \eta \cdot f_{c} b \cdot x \cdot \cos ^{2} \theta_{c}$

Force $C$ must be equal to the tension force in the bottom reinforcement $T=\sigma_{s} A_{s}$, where $\sigma_{s}$ is the stress in the reinforcement and $A_{s}$ is the cross-sectional area of the reinforcement. Stress $\sigma_{s}$ is evaluated from strain $\varepsilon_{\mathrm{s}}$ by using a bi-linear stress-strain relationship for the steel (elastic-plastic or elastic with strain hardening).

The last assumption of the proposed model concerns the flexural compression reinforcement in the end sections. As illustrated earlier in Fig. 4, in short coupling beams with large amounts of stirrups this reinforcement typically works with small tensile stresses due to the propagation of diagonal shear cracks across the shear span [5]. Because the reinforcement works with small stresses, it does not contribute significantly to the resistance of the section and therefore it will be neglected in the calculations. Taking this into account, the flexural capacity of the section can be expressed as:

$M_{\max }=T \cdot z=T(d-\lambda x / 2)$

and the corresponding shear $\mathrm{V}_{\max }=2 \mathrm{M}_{\max } / \mathrm{a}$. This expression assumes a single layer of tension reinforcement at the bottom of the section, while the approach can be easily extended to also account for longitudinal web reinforcement. As indicated in Fig. 10, the tensile strains in the web reinforcement are calculated 
on the basis of the linear strain diagram, and these strains are used to evaluate the stress and tensile force in the reinforcement.

With the above assumptions, the proposed method can be summarized in the following manner: The method is identical to the classical flexural strength model for slender members with the following three important differences:

(1) The strains in the compression zone of the end sections are interpreted as being inclined at angle $\theta_{c}$ with respect to the horizontal axis.

(2) The width of the compression zone b is replaced with an effective reduced width $\mathrm{b} \cos ^{2} \theta_{\mathrm{c}}$ (see Eq. (5)).

(3) The flexural-compression reinforcement is neglected.

These modifications account for the effects of the shear force on the flexural capacity of the end sections of short coupling beams. As the effective compression zone is narrower and the compression reinforcement neglected, the model will predict a deeper compression zone than the classical flexural model. This in turn results in a reduced lever arm between the longitudinal forces $\mathrm{T}$ and $\mathrm{C}$ and $\mathrm{a}$ reduced moment capacity due to the action of the shear force. In addition, because the proposed model resembles the classical model for flexure, it also has the potential to capture the effect of axial compression forces. In coupled wall structures such forces develop due to the large stiffness of the walls which restrain the axial elongation of the coupling beams caused by cracking and yielding. However, as the available tests of coupling beams are performed almost exclusively without axial restraint, and because the compression forces are typically neglected in design, this study focuses on unrestrained beams.

\subsection{Comparisons with tests}

The solution of the proposed model will be demonstrated on test specimen 312. As mentioned earlier, the main unknown of the method is the depth of the compression zone $\mathrm{x}$. The value of $\mathrm{x}$ is determined through an iterative solution procedure that establishes the equilibrium of the horizontal forces in the critical end sections of the beam. To begin the calculations, it is assumed that $\mathrm{x} \approx 0.4 \mathrm{~d} \approx 300 \mathrm{~mm}$. Taking into account the linear variation of the strains in the section and the top strain of $-3.5 \times 10^{-3}$, the strain in the flexural tension reinforcement is $\varepsilon_{\mathrm{s}}=-3.5 \times 10^{-3}(1-\mathrm{d} / \mathrm{x})=$ $4.83 \times 10^{-3}$. This value exceeds the yield strain of the steel, and therefore the stress $\sigma_{s}$ is equal to the yield strength $\mathrm{f}_{\mathrm{y}}=313 \mathrm{MPa}$, or it can be slightly higher if the strain hardening of the steel is taken into account. As the resulting force in the reinforcement $\mathrm{T}=\mathrm{A}_{\mathrm{s}} \sigma_{\mathrm{s}}=537 \mathrm{kN}$ must equal C, Eq. (5) is used to calculate a new value of $\mathrm{x}$. The equation requires the calculation of factors $\lambda$ and $\eta$ from Eq. (2) and (3) as well as angle $\theta_{c}$ from Eq. (1). With calculated $\lambda=0.90$ and $\eta=0.81$, the lever arm of the internal forces $z$ is $(\mathrm{d}-\lambda \mathrm{x} / 2)=579 \mathrm{~mm}$ and the angle of the principal compressive stresses $\theta_{\mathrm{c}}$ is $48.7^{\circ}$. Alternatively, to simplify the calculations, angle $\theta_{\mathrm{c}}$ can be kept constant by assuming $\mathrm{z} \approx 0.9 \mathrm{~d}$. With $\theta_{\mathrm{c}}=48.7^{\circ}$, the new value of $x$ is $316 \mathrm{~mm}$, and this value is used to repeat the calculations until $x$ converges to $313 \mathrm{~mm}$. The final value of $\mathrm{x}$ is used together with the maximum compressive strain of $-3.5 \times 10^{-3}$ to draw the straight strain line in Fig. 9b. It can be seen that the prediction approximates well the strain profile obtained from the FE model. Note again that the goal is to approximate the principal compressive stresses in the top of the section and the horizontal tensile strain in the bottom reinforcement. Similarly adequate are the strain predictions for shorter and longer beams as shown in Fig. 9a and c, respectively.

Having obtained the depth $\mathrm{x}$ and force $\mathrm{T}$ for beam 312, the flexural capacity of the end section taking into account the effect of shear is calculated from Eq. (6) at $308 \mathrm{kN} \cdot \mathrm{m}$. This value is divided by one-half the shear span $\mathrm{a} / 2=0.508 \mathrm{~m}$ to obtain the predicted shear force at failure $V_{\max }=606 \mathrm{kN}$. Therefore, the proposed model produces an experimental-to-predicted strength ratio of $642 / 606=1.06$. For comparison, a flexural calculation that neglects the effects of shear results in a ratio of 0.79 , while the strut-and-tie model in Fig. 1b produces a ratio of 1.17.

It is also of interest to study how the proposed model captures the effect of different test variables. As discussed earlier, the strength of short coupling beams with variable transverse reinforcement remains constant provided that the amount of stirrups is sufficient to prevent diagonal tension failures. Since the proposed model focuses on the vertical end sections, it does not include the transverse reinforcement. The prediction of the model for beams $311-313$ with $\rho_{\mathrm{v}}$ between $0.88 \%$ and $2.52 \%$ is shown in Fig. 3 together with the measured strengths of the specimens. It can be seen that the new model captures very well the test results.

Another variable that can be studied with the help of the tests by Paulay [4] is the shear-span-to-effective-depth ratio. Fig. 11 shows the variation of the shear strength of beams 393, 312, and 244 as a function of a/d from 1.11 to 2.27. As mentioned earlier, the three beams failed in sliding shear and showed a significant decrease of shear resistance with increasing a/d. The experimental results are compared to the predictions of the classical flexural model, the strut-and-tie model, and the new mechanical model for shear-flexure interaction. It can be seen that the proposed model captures well the test results while the strut-and-tie model is conservative. The flexural model produces a very unconservative prediction for the shortest beam and the predictions improve as the a/d ratio increases. This is due to the diminishing effect of the shear force on the flexural resistance of the end sections. In slender beams the shear force is relatively small as compared to the longitudinal forces $\mathrm{T}$ and $\mathrm{C}$ in the section, and therefore its effect is negligible. In this regard, it is important to note that the proposed mechanical model converges to the classical flexural model when applied to slender beams. This is because as a/d increases, the angle $\theta_{c}$ of the principal compressive stresses decreases, and therefore the reduction factor $\cos ^{2} \theta_{c}$ in Eq. (5) approaches unity.

Finally, the proposed model is applied to a database of 24 tests of short coupling beams collected from the literature ([4-11]), see Table 2. The beams featured rectangular cross sections and conventional orthogonal reinforcement without diagonal bars. Only beams that exhibited failure modes different than diagonal tension are included in the database. As shown in the table, the reported failure modes were mainly flexure as well as shear sliding and

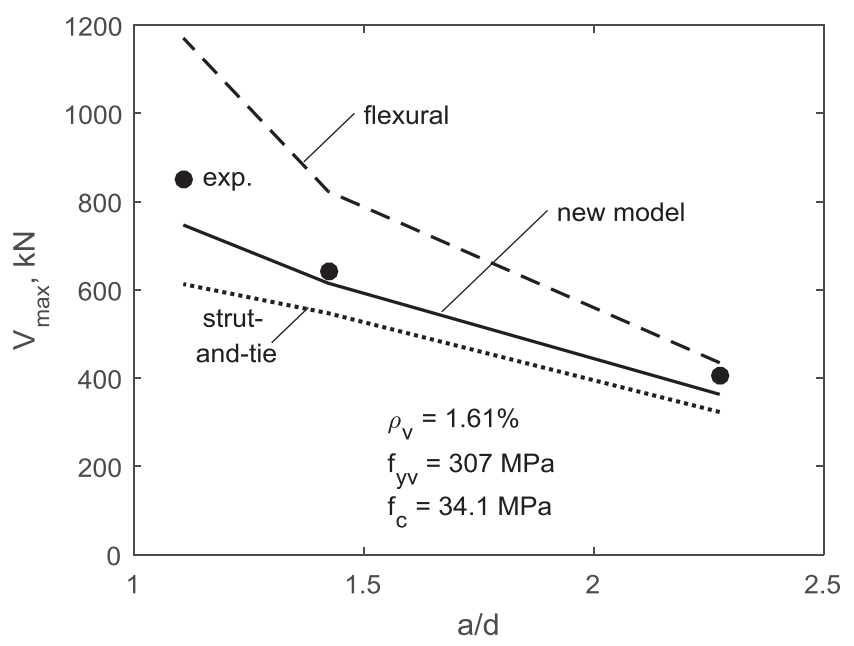

Fig. 11. Effect of a/d ratio on the sliding shear strength of short coupling beams (tests by Paulay [4]). 
Table 2

Database of 24 tests of short coupling beams.

\begin{tabular}{|c|c|c|c|c|c|c|c|c|c|c|c|c|c|c|c|c|c|c|c|c|c|c|c|}
\hline \multirow{2}{*}{$\begin{array}{l}\text { Ref.\# \& } \\
\text { year }\end{array}$} & \multirow{2}{*}{$\begin{array}{l}\text { Beam } \\
\text { name }\end{array}$} & \multirow[t]{2}{*}{$a / d$} & \multirow{2}{*}{$\begin{array}{l}\mathrm{b} \\
(\mathrm{mm})\end{array}$} & \multirow{2}{*}{$\begin{array}{l}\mathrm{d} \\
(\mathrm{mm})\end{array}$} & \multirow{2}{*}{$\begin{array}{l}\mathrm{h} \\
(\mathrm{mm})\end{array}$} & \multirow{2}{*}{$\begin{array}{l}\rho_{1} \\
(\%)\end{array}$} & \multirow[t]{2}{*}{$\mathrm{n}_{\mathrm{b}}$} & \multirow[t]{2}{*}{$f_{y}$} & \multirow[t]{2}{*}{$f_{u} / f_{y}$} & \multirow[t]{2}{*}{$\varepsilon_{\mathrm{u}}$} & \multirow{2}{*}{$\begin{array}{l}\mathrm{f}_{\mathrm{c}} \\
(\mathrm{MPa})\end{array}$} & \multirow{2}{*}{$\begin{array}{l}\rho_{\mathrm{v}} \\
(\%)\end{array}$} & \multirow{2}{*}{$\begin{array}{l}\mathrm{f}_{\mathrm{yv}} \\
(\mathrm{MPa})\end{array}$} & \multirow{2}{*}{$\begin{array}{l}\text { \# of } \\
\text { layers }\end{array}$} & \multirow{2}{*}{$\begin{array}{l}\mathrm{A}_{\mathrm{s}} / \text { layer } \\
\left(\mathrm{mm}^{2}\right)\end{array}$} & \multirow{2}{*}{$\begin{array}{l}\mathrm{f}_{\mathrm{yh}} \\
\text { (MPa) }\end{array}$} & \multirow{2}{*}{$\begin{array}{l}\text { Load } \\
\text { type }\end{array}$} & \multirow{2}{*}{$\begin{array}{l}\text { Flex. } \\
\text { yielding }\end{array}$} & \multirow{2}{*}{$\begin{array}{l}\text { Rep. } \\
\text { mode }\end{array}$} & \multirow{2}{*}{$\begin{array}{l}V_{\exp } \\
(k N)\end{array}$} & \multicolumn{3}{|c|}{$\mathrm{V}_{\text {exp }} / \mathrm{V}_{\text {pred }}$} \\
\hline & & & & & & & & & & & & & & & & & & & & & Flexural & STM & $\begin{array}{l}\text { New } \\
\text { model }\end{array}$ \\
\hline \multirow{9}{*}{$\begin{array}{l}4,5], \\
1969\end{array}$} & $\# 242$ & 2.27 & 152 & 536 & 610 & 1.82 & 4 & 321 & 1.52 & $0.10^{\mathrm{a}}$ & 38.0 & 0.88 & 386 & 0 & & & $\mathrm{M}$ & $\mathrm{Y}$ & SC & 396 & 0.92 & 1.22 & 1.08 \\
\hline & \#243 & 2.27 & 152 & 536 & 610 & 1.82 & 4 & 321 & 1.52 & $0.10^{\mathrm{a}}$ & 31.4 & 0.88 & 386 & 0 & & & $\mathrm{C}$ & $\mathrm{Y}$ & $\mathrm{S}$ & 372 & 0.86 & 1.18 & 1.06 \\
\hline & \#244 & 2.27 & 152 & 536 & 610 & 1.82 & 4 & 321 & 1.52 & $0.10^{\mathrm{a}}$ & 36.3 & 1.58 & 307 & 0 & & & C & Y & $\mathrm{s}$ & 405 & 0.94 & 1.25 & 1.12 \\
\hline & \#312 & 1.42 & 152 & 714 & 787 & 1.58 & 4 & 313 & 1.55 & $0.10^{\mathrm{a}}$ & 35.2 & 1.65 & 285 & 0 & & & c & $\mathrm{Y}$ & S & 642 & 0.79 & 1.17 & 1.04 \\
\hline & \#313 & 1.42 & 152 & 714 & 787 & 1.58 & 4 & 313 & 1.55 & $0.10^{\mathrm{a}}$ & 44.5 & 2.52 & 314 & 0 & & & C & $\mathrm{Y}$ & $\mathrm{S}$ & 660 & 0.81 & 1.16 & 1.01 \\
\hline & \#314 & 1.42 & 152 & 714 & 787 & 1.58 & 4 & 313 & 1.55 & $0.10^{\mathrm{a}}$ & 44.7 & 2.52 & 314 & 2 & 400 & 314 & c & $\mathrm{Y}$ & $\mathrm{s}$ & 736 & 0.76 & 1.29 & 1.03 \\
\hline & \#315 & 1.42 & 152 & 714 & 787 & 1.58 & 4 & 313 & $1.55^{\mathrm{a}}$ & $0.10^{\mathrm{a}}$ & 37.9 & 2.43 & 321 & $2^{\mathrm{a}}$ & $400^{\mathrm{a}}$ & $314^{\mathrm{a}}$ & $\mathrm{C}^{\mathrm{a}}$ & $\mathrm{Y}$ & SC & 774 & 0.81 & 1.40 & 1.13 \\
\hline & \#393 & 1.11 & 152 & 917 & 991 & 1.06 & 4 & 316 & 1.55 & $0.10^{\mathrm{a}}$ & 30.8 & 1.62 & 328 & 3 & 258 & 328 & C & $\mathrm{N}$ & S-SC & 849 & 0.85 & 1.38 & 1.14 \\
\hline & $\# 394$ & 1.11 & 152 & 917 & 991 & 1.06 & 4 & 316 & 1.55 & $0.10^{\mathrm{a}}$ & 43.2 & 2.52 & 314 & $3^{\mathrm{a}}$ & $400^{\mathrm{a}}$ & $314^{\mathrm{a}}$ & C & $\mathrm{N}$ & SC & 1041 & 0.91 & 1.61 & 1.20 \\
\hline [6], 1996 & CB-1B & 1.88 & 130 & 266 & 300 & 0.65 & 2 & 484 & 1.59 & $0.10^{\mathrm{a}}$ & 33.0 & 1.03 & 296 & 1 & 57 & 281 & C & $\mathrm{Y}$ & SC & 124 & 0.97 & 1.27 & 1.10 \\
\hline \multirow{2}{*}{ [7], 2000} & P01 & 1.61 & 150 & 372 & 400 & 0.52 & 4 & 567 & 1.16 & $0.10^{\mathrm{a}}$ & 48.9 & 0.84 & 567 & 1 & 57 & $567^{a}$ & M & Y & _- & 224 & 1.01 & 1.27 & 1.10 \\
\hline & $\mathrm{P} 02$ & 1.61 & 150 & 372 & 400 & 0.52 & 4 & 567 & 1.16 & $0.10^{\mathrm{a}}$ & 44.5 & 0.84 & 567 & 1 & 57 & $567^{\mathrm{a}}$ & $C$ & $\mathrm{Y}$ & - & 237 & 1.07 & 1.36 & 1.18 \\
\hline [8], 2002 & MCB2 & 1.52 & 120 & 461 & 500 & 0.50 & 3 & 524 & 1.21 & $0.10^{\mathrm{a}}$ & 44.9 & 1.07 & 346 & 2 & 101 & 330 & $\mathrm{M}$ & Y & $\mathrm{F}$ & 260 & 1.11 & 1.58 & 1.25 \\
\hline & MCB3 & 1.94 & 120 & 361 & 400 & 0.52 & 2 & 525 & 1.21 & $0.10^{\mathrm{a}}$ & 38.9 & 1.07 & 346 & 1 & 101 & 330 & $\mathrm{M}$ & $\mathrm{Y}$ & $\mathrm{F}$ & 159 & 1.15 & 1.49 & 1.25 \\
\hline & MCB4 & 2.25 & 120 & 311 & 350 & 0.57 & 3 & 521 & 1.22 & $0.10^{\mathrm{a}}$ & 39.7 & 1.07 & 346 & 1 & 101 & 330 & M & $\mathrm{Y}$ & $\mathrm{F}$ & 140 & 1.26 & 1.63 & 1.34 \\
\hline [9], 2002 & СCB2 & 1.52 & 120 & 461 & 500 & 0.50 & 3 & 524 & $1.2^{\mathrm{a}}$ & $0.10^{\mathrm{a}}$ & 37.8 & 1.07 & 346 & 2 & 101 & 346 & C & $\mathrm{Y}$ & SC & 227 & 0.97 & 1.40 & 1.13 \\
\hline & ССB3 & 1.94 & 120 & 361 & 400 & 0.64 & 3 & 524 & $1.2^{\mathrm{a}}$ & $0.10^{\mathrm{a}}$ & 37.8 & 1.07 & 346 & 1 & 101 & 346 & c & $\mathrm{Y}$ & $\mathrm{s}$ & 165 & 0.99 & 1.30 & 1.11 \\
\hline & ССB4 & 2.25 & 120 & 311 & 350 & 0.57 & 3 & 521 & $1.2^{\mathrm{a}}$ & $0.10^{\mathrm{a}}$ & 37.8 & 1.07 & 346 & 1 & 101 & 346 & C & $\mathrm{Y}$ & $\mathrm{F}$ & 123 & 1.10 & 1.43 & 1.18 \\
\hline & CCB12 & 1.25 & 120 & 561 & 600 & 0.50 & 3 & 525 & $1.2^{\mathrm{a}}$ & $0.10^{\mathrm{a}}$ & 37.8 & 1.61 & 346 & 2 & 101 & 346 & C & $\mathrm{Y}$ & S & 317 & 0.94 & 1.37 & 1.15 \\
\hline [10], & CBF1 & 3.05 & 316 & 524 & 600 & 3.38 & 8 & 563 & 1.25 & $0.10^{\mathrm{a}}$ & 80.3 & 2.11 & 422 & 2 & 2800 & 563 & C & $\mathrm{N}$ & SC & 1918 & 0.78 & 1.44 & 1.00 \\
\hline 2016 & CBF2 & 3.05 & 400 & 524 & 600 & 2.67 & 8 & 563 & 1.25 & $0.10^{\mathrm{a}}$ & 80.3 & 1.67 & 422 & 2 & 2800 & 563 & C & $\mathrm{N}$ & SC & 1992 & 0.80 & 1.35 & 0.94 \\
\hline & CBF3 & 3.05 & 400 & 524 & 600 & 2.67 & 8 & 563 & 1.25 & $0.10^{\mathrm{a}}$ & 66.5 & 1.67 & 422 & 2 & 2800 & 563 & C & $\mathrm{N}$ & SC & 1830 & 0.74 & 1.31 & 0.93 \\
\hline [11]. & CB10-2 & 1.15 & 250 & 433 & 500 & 1.52 & 3 & 470 & $1.3^{\mathrm{a}}$ & $0.10^{\mathrm{a}}$ & 36.1 & 1.06 & 468 & 2 & 265 & 468 & c & $\mathrm{N}$ & SC & 874 & 1.11 & 1.09 & 1.11 \\
\hline 2016 & CB20-2 & 2.33 & 300 & 429 & 500 & 2.04 & 3 & 450 & $1.3^{\mathrm{a}}$ & $0.10^{\mathrm{a}}$ & 52.2 & 1.26 & 502 & 2 & 265 & 502 & C & $\mathrm{Y}$ & F-S & 1098 & 1.00 & 1.48 & 1.20 \\
\hline & & & & & & & & & & & & & & & & & & & & $A v g=$ & 0.94 & 1.35 & 1.12 \\
\hline
\end{tabular}

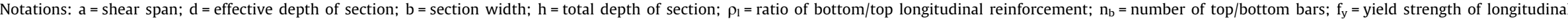

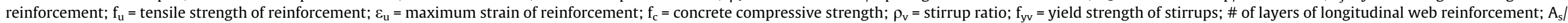
layer $=$ steel area per layer; $\mathrm{f}_{\mathrm{yh}}=$ yield strength of longitudinal web reinforcement; $\mathrm{V}_{\mathrm{exp}}=$ measured shear strength, $\mathrm{V}_{\mathrm{pred}}=$ predicted shear strength.

Load type: M - monotonic; C - reversed cyclic. Reported failure modes: SC - shear compression; S - sliding shear; F - flexure; F-S - flexure-shear

a Estimated values which were not provided in the original publication. 


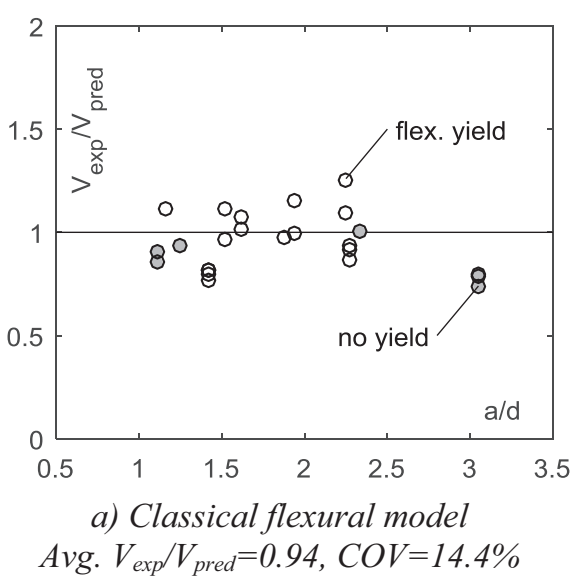

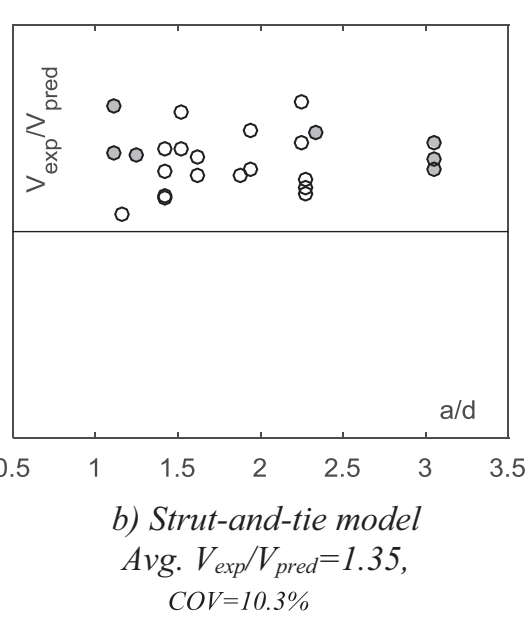

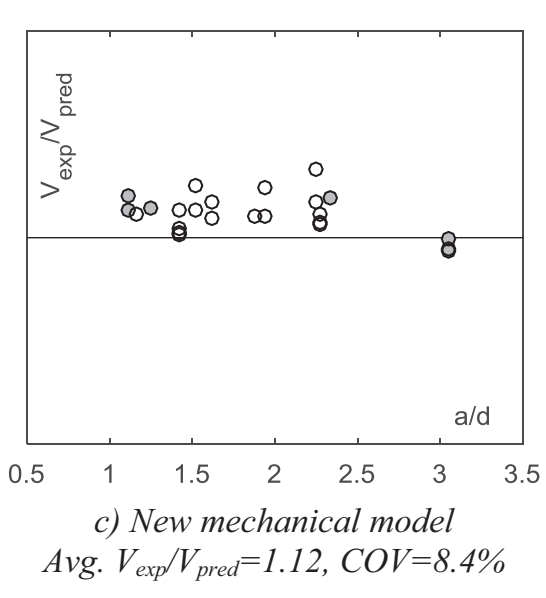

Fig. 12. Shear strength experimental-to-predicted ratios for 24 tests of short coupling beams.

diagonal compression with or without yielding of the longitudinal reinforcement. The a/d ratio of the beams varies from 1.11 to 3.05 , the effective depth $\mathrm{d}$ from $266 \mathrm{~mm}$ to $917 \mathrm{~mm}$, the concrete compressive strength $\mathrm{f}_{\mathrm{c}}$ from $30.8 \mathrm{MPa}$ to $80.3 \mathrm{MPa}$, the ratio of bottom/top longitudinal reinforcement $\rho_{1}$ from $0.50 \%$ to $3.38 \%$, and the ratio of transverse reinforcement $\rho_{v}$ from $0.84 \%$ to $2.52 \%$. While strictly speaking the new model is not applicable to beams with a/d larger than about 2.5, three beams with a/d of 3.05 are included in the database as exceptional cases. The table also lists the measured strength of the beams $V_{\exp }$ as well as the shear strength experimental-to-predicted ratios produced by the classical flexural model, the strut-and-tie model, and the mechanical model for shear-flexure interaction. The predictions of the flexural model and the shear-flexure interaction model were obtained by taking into account the longitudinal web reinforcement of the beams as well as the strain hardening of the reinforcement.

The $V_{\text {exp }} / V_{\text {pred }}$ ratios are plotted in Fig. 12 as a function of the $\mathrm{a} / \mathrm{d}$ ratio of the beams. It can be seen from plot 12a that the classical flexural model tends to be unconservative in the range $\mathrm{a} / \mathrm{d}<1.5$ and for beams that failed prior to yielding of the longitudinal reinforcement. Consistent with the previous results, the strutand-tie model produces conservative strength predictions across the entire range of a/d ratios with an average $\mathrm{V}_{\text {exp }} / \mathrm{V}_{\text {pred }}$ ratio of 1.35 and a coefficient of variation (COV) of $10.3 \%$. By comparing Fig. $12 \mathrm{~b}$ and c, it can be seen that the proposed mechanical model for shear-flexure interaction significantly improves these results. The average $\mathrm{V}_{\text {exp }} / \mathrm{V}_{\text {pred }}$ becomes 1.12 and the COV reduces to $8.4 \%$. The results show no apparent bias of the model with respect to the a/d ratio and with regards to whether the reinforcement yields or not. The predictions for the three specimens with a/d of 3.05 are slightly unconservative probably because these beams are just outside the range of applicability of the model. In more slender beams the concrete can fail in diagonal compression away from the end sections due to the compression softening effect. It should be highlighted that these excellent results are obtained on the basis of a simple flexure-like model that accounts for the apparent complex interaction between bending moment and shear in the critical end sections of short coupling beams. If the proposed model is combined with an appropriate model for diagonal tension failures in coupling beams, it can form a complete approach that adequately captures all possible failure modes of such important members.

\section{Conclusions}

This paper presented a new mechanical model for the shearflexure interaction in the critical end sections of short coupling beams with conventional reinforcement. The model is aimed at combining accuracy and simplicity for evaluating the resistance against sliding shear and diagonal compression failures. The following conclusions were reached based on comparisons with tests and other models:

(1) Nonlinear FE models based on the disturbed stress field model can capture the complete behaviour of coupling beams exhibiting sliding shear and diagonal compression failures.

(2) The classical flexural model based on the plane-sectionsremain-plane hypothesis overestimates the flexural strength of the end sections of short coupling beams as it does not account for the effect of the high shear force in the section.

(3) The strut-and-tie approach produces reasonably conservative predictions of shear strength provided that the geometry of the model is selected to maximize the predictions. More precisely, it is proposed to choose the size of the nodal zones in the adjacent shear walls such that to ensure the simultaneous crushing of the struts and yielding of the longitudinal reinforcement.

(4) The proposed mechanical model maintains the simplicity of the classical flexural approach while it improves significantly the strength predictions of both the flexural and strut-and-tie models. When applied to a database of 24 short coupling beams, the model produced an average shear strength experimental-to-predicted ratio of 1.12 and a COV of $8.4 \%$.

(5) The proposed model also estimates the strains in the critical sections that can be used for evaluating the displacement capacity and ductility of short coupling beams.

\section{References}

[1] Paulay T, Priestley MJN. Seismic design of reinforced concrete and masonry buildings. New York: John Wiley \& Sons; 1992.

[2] Lee OJ, Kuchma DA, Baker W, Novak LC. Design and analysis of heavily loaded reinforced concrete link beams for Burj Dubai. ACI Struct J 2008;105(4):451-9.

[3] ACI Committee 318-14. Building code requirements for structural concrete (ACI 318-14) and commentary. Farmington Hills: American Concrete Institute; 2011.

[4] Paulay T. The coupling of shear walls. Ph.D. thesis. Christchurch (New Zealand): University of Canterbury; 1969.

[5] Paulay T. Coupling beams of reinforced concrete shear walls. J Struct Div, ASCE 1971;97(ST3):843-62.

[6] Tassios TP, Moretti M, Bezas A. On the behavior and ductility of reinforced concrete coupling beams of shear walls. ACI Struct J 1996;93(S68):711-9.

[7] Galano L, Vignoli A. Seismic behavior of short coupling beams with different reinforcement layouts. ACI Struct J 2000;97(S89):876-85. 
[8] Kwan AKH, Zhao ZZ. Testing of coupling beams with equal end rotations maintained and local joint deformation allowed. Proc Inst Civ Eng: Struct Build 2002;152(1):67-78

[9] Kwan AKH, Zhao ZZ. Cyclic behaviour of deep reinforced concrete coupling beams. Proc Inst Civ Eng: Struct Build 2002;152(3):289-93.

[10] Fisher AW. Shear performance of heavily reinforced high-strength concrete coupling beams. Master thesis. Toronto (Canada): University of Toronto; 2016.

[11] Lim E, Hwang S, Wang T, Chang Y. An investigation on the seismic behavior of deep reinforced concrete coupling beams. ACI Struct J 2016;113(2):1-10.

[12] CEB-FIP Model Code. Fib model code for concrete structures 2010. NJ (USA): Ernst \& Sons; 2013.

[13] EN 1992-1-1 Eurocode 2: design of concrete structures - Part 1-1: general rules and rules for buildings. European Committee for Standardization; 2004.
[14] Vecchio FJ. Disturbed stress field model for reinforced concrete: formulation. J Struct Eng 2000;106(9):1070-7.

[15] Vecchio FJ, Collins MP. The modified compression field theory for reinforced concrete elements subjected to shear. ACI J Proc 1986;83(2):219-31.

[16] Bentz EC. Sectional analysis of reinforced concrete members. Ph.D. thesis Toronto (Canada): Department of Civil Engineering, University of Toronto; 2000.

[17] Popovics S. A numerical approach to the complete stress-strain curve of concrete. Cem Concr Res 1973;3(5):583-99.

[18] Collins MP, Mitchell D. Prestressed concrete structures. Toronto and Montreal (Canada): Response Publications; 1997. 